\title{
Varietal Differences in Susceptibility to Bacterial Spot (Xanthomonas arboricola pv. pruni) among 69 Peach Cultivars and Selections as Evaluated by Artificial Inoculation to Shoots
}

\author{
Yuko Suesada*, Masahiko Yamada, Takayoshi Yamane, Eisuke Adachi**, Hideaki Yaegaki \\ and Masami Yamaguchi***
}

NARO Institute of Fruit Tree Science, Tsukuba 305-8605, Japan

\begin{abstract}
Peach (Prunus persica) shoots were artificially inoculated with stone fruit bacterial spot bacteria (Xanthomonas arboricola pv. pruni) to evaluate varietal differences in peach genetic resources for their susceptibility to this disease. Current shoots of cultivars/selections were wounded, a bacterial suspension was injected by a syringe attached to multiple needles, and lesion length was measured a few months later. Inoculation was carried out in May, June and July with two concentrations of bacterial suspension: $10^{6} \mathrm{cfu} \cdot \mathrm{mL}^{-1} \mathrm{or} 10^{8} \mathrm{cfu} \cdot \mathrm{mL}^{-1}$. Although the effect of inoculation time was not significant and the effect of inoculum concentration was significant, inoculation in June at a concentration of $10^{8} \mathrm{cfu} \cdot \mathrm{mL}^{-1}$ was the most suitable treatment. Among 69 cultivars/selections tested, there was no immune cultivar, however; there were varietal differences in susceptibility to bacterial spot. 'Nishiki' and 'Mochizuki', two cultivars for canning use, 'Chimarrita', a Brazilian cultivar, and 'Tsukikagami', a table peach cultivar, were relatively resistant and may be useful sources for breeding aimed at disease resistance.
\end{abstract}

Key Words: disease resistance, genetic resources, Prunus persica.

\section{Introduction}

Bacterial spot caused by Xanthomonas arboricola pv. pruni is one of the most important and serious diseases of peaches grown in areas with a lot of wind and rain. It also attacks other stone fruit crops. The symptoms of the disease are defoliation and spots on the leaves, twigs, and fruit. Leaf spots and severe defoliation damage growing trees, and spots on the fruit reduce the peaches' commercial value. Since complete control by chemical application is difficult, the use of resistant cultivars is considered to be the most effective way to control this disease; however, immune cultivars are not known or used in Japan.

In other areas where stone fruits are grown, the susceptibility of cultivars to bacterial spot was evaluated and varietal differences were reported by Du Plessis

Received; February 23, 2013. Accepted; June 24, 2013.

* Corresponding author (E-mail: suesada@affrc.go.jp).

** Present address: Horticultural Experimental Station, Yamagata Integrated Agricultural Research Center, Sagae 991-0043, Japan.

*** Present address: Faculty of Agriculture, Tokyo University of Agriculture, Atsugi 243-0034, Japan.
(1988), Keil and Fogle (1974), Martins and Raseira (1996), Medeiros et al. (2011), Randhawa and Civerolo (1985), Sherman and Lyrene (1981), and Werner et al. (1986). Similarly in Japan, orchard susceptibility of economically important cultivars has been examined several times; Yamamoto et al. (1953), Kuraoka and Kato (1955), Shiina et al. (1966), and Takanashi (1978) reported relatively resistant cultivars. However, the cultivation area of those cultivars has not increased. Additionally, breeding for disease resistance was not easy with little chance for success and the major objective of the breeding program was to improve fruit eating quality. So breeding for bacterial spot disease resistance has not been a top priority. In recent times, the commercially cultivated varieties have changed, and most currently grown cultivars have not been evaluated for their susceptibility to bacterial spot. Therefore, it is necessary to evaluate the susceptibilities of peach cultivars and selections in order to select breeding materials.

Since evaluation under field conditions is prone to be affected by climatic conditions and the density of the causal bacteria, it is advisable to evaluate trees using artificial inoculation. Topp et al. (1991) compared rating 
methods, including measurements of the number, size and incidence of leaf spots, percentage affected leaf area and stem canker spot length, and concluded that measuring the length of stem cankers at the injection sites was a simple and reproducible method. Miyake et al. (1999) made improvements to the artificial inoculation method using multiple needles on shoots and reported varietal differences in the resistance of Japanese plum (Prunus salicina), apricot (Prunus armeniaca), and a small number of peach cultivars to bacterial spot.

Bacterial spot causes spring canker, and summer canker on peach shoots. Spring canker is the main source of primary infection, and summer canker is a secondary cause (Takanashi, 1978). Since infection occurs during autumn of the previous year and the overwintered lesion becomes a spring canker, it takes a longer time from infection to measurement for spring canker than summer canker. Furthermore, spring canker may be affected by the environment. Since summer canker is easier to measure, this study focused on measuring summer canker after shoot inoculation.

Therefore, the objectives of this study were to evaluate: 1) the varietal differences in shoots for bacterial spot disease using the artificial inoculation method of Miyake et al. (1999) with multiple needles on shoots in peach genetic resources mainly consisting of peach cultivars that have been used in commercial production in Japan and selections from the NARO Institute of Fruit Tree Science (NIFTS) peach breeding program, and 2) the effects of different times of inoculation and concentrations of inoculum on the lesion length.

\section{Materials and Methods}

\section{Plant material}

Peach cultivars from the genetic resources collections and breeding selections grown as independent trees at NIFTS, Tsukuba, Ibaraki, Japan, were used. Tree ages ranged from 3 to 14 years old.

\section{Inoculum}

Xanthomonas arboricola pv. pruni (MAFF301420), supplied by the National Institute of Agrobiological Sciences, was the inoculant. Bacteria growing on potato dextrose agar were suspended in sterile water and adjusted to two different concentrations.

\section{Inoculation}

A syringe with ten 26-gauge needles was used to injure and inject the bacterial suspension at each site. Several current shoots, $30-40 \mathrm{~cm}$ long with basal diameters of about $5 \mathrm{~mm}$, on trees growing in the field were artificially inoculated (Fig. 1). Three points at intervals of $7 \mathrm{~cm}$ per shoot, 3 shoots per treatment were lightly wounded by pricking the shoot surface with needles and injected with the bacterial suspension using multiple needles as described in the three sections below.

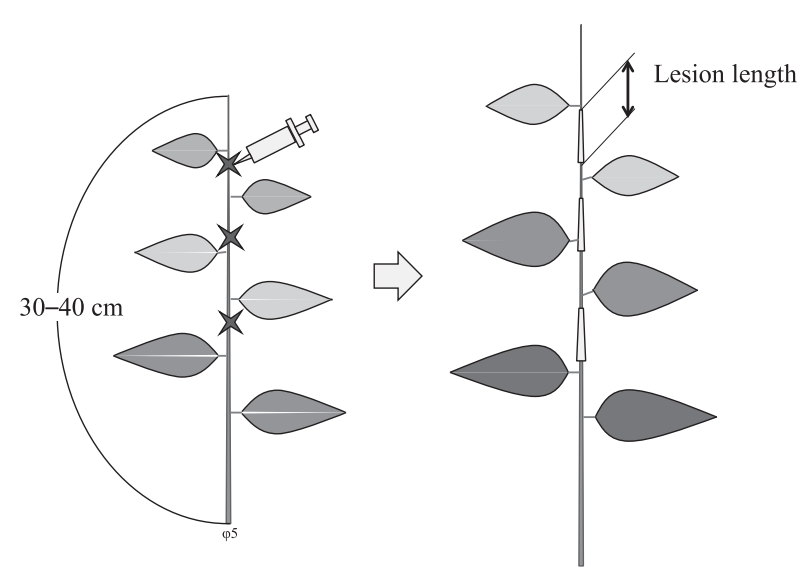

Fig. 1. Inoculation of shoots. Left: shoot at the time of inoculation. Right: shoot at the time of lesion length measurement.

\section{Yearly effect and the genotype $x$ year interaction for lesion length (Exp. 1)}

Twenty-five peach cultivars listed in Table 1 were tested repeatedly for three years from 2006 to 2008 . Current shoots were chosen in June and were subjected to multiple-needle injection of the bacterial suspension at a concentration of $10^{8} \mathrm{cfu} \cdot \mathrm{mL}^{-1}$. Inoculated shoots were collected, lesion lengths were measured in late August or early September and the average length $(X)$ was calculated for each shoot.

Current shoots of 9 cultivars ('Mochizuki', 'Manami', 'Masahime', 'Nishiki', 'Natsuotome', 'Chiyohime', 'Shimizu Hakuto', 'Akatsuki', and 'Harrow Beauty') were wounded and injected with sterile water as the control in the same way as the artificially inoculated shoots in 2006. The average lesion length was $5.5 \mathrm{~mm}$ for the 9 cultivars. Therefore, the value of $(X-5.5)$ was used as the value showing the effect of the bacterial inoculation. In addition, as the average and standard deviation were correlated, $\log _{10}(X-5.5)$ were used for statistical analysis (the shoot measured value). $\log _{10}(X$ -5.5 ) values of each cultivar in each year were subjected to analysis of variance (ANOVA). The model adopted here to express the measurement value is shown below:

$$
P_{i j k}=\mu+g 1_{i}+y_{j}+(g y)_{i j}+e 1_{i j k}
$$

where $P_{i j k}$ is the shoot measured value of the $i$ th genotype of the $j$ th year; $\mu$ is a constant value (the overall mean); $g l_{i}$ is the random effect contributed by the $i$ th genotype; $y_{j}$ is the random effect contributed by the $j$ th year; $(g y)_{i j}$ is the interaction between the $i$ th genotype and the $j$ th year; $e l_{i j k}$ is the error in the $k$ th shoot of the $i$ th genotype in the $j$ th year.

Distribution of the error estimate, which was obtained as the deviation of each shoot measured value from the average shoot measured value in a cultivar and year, approached normal distribution with the KolmogorovSmirnov one-sample test at $(P=0.05)$. 
Table 1. Peach cultivars/selections used in the present study.

\begin{tabular}{|c|c|c|c|c|c|c|c|}
\hline \multirow[b]{2}{*}{ Cultivar/selection } & \multirow[b]{2}{*}{ Exp. 1} & \multirow[b]{2}{*}{ Exp. 2} & \multirow[b]{2}{*}{ Exp. 3} & \multicolumn{2}{|c|}{ Pedigree } & \multirow{2}{*}{$\begin{array}{l}\text { Year of cultivar registration or } \\
\text { appearing in commercial or } \\
\text { test production }{ }^{2}\end{array}$} & \multirow[b]{2}{*}{ Origin } \\
\hline & & & & Seed parent & Pollen parent & & \\
\hline \multicolumn{8}{|c|}{ Table peach cultivar/selection } \\
\hline Shanghai Suimitao & & $\bigcirc$ & & & & - & China \\
\hline Tianjin Suimitao & & $\bigcirc$ & & & & - & China \\
\hline Doyo & & $\bigcirc$ & & & seedling & 1897 & Okayama \\
\hline Denjuro & & $\bigcirc$ & & & & 1898 & Kanagawa \\
\hline Hakuto & & $\bigcirc$ & & & seedling & 1899 & Okayama \\
\hline Rikaku & & $\bigcirc$ & & Shanghai Suimitao O.P. ${ }^{y}$ & & 1900 & Okayama \\
\hline Tachibana Wase & & $\bigcirc$ & & Denjuro O.P. & & 1910 & Kanagawa \\
\hline Koyo Hakuto & & $\bigcirc$ & & & seedling & 1927 & Okayama \\
\hline Hakuho & & $\bigcirc$ & & Hakuto & Tachibana Wase & 1933 & Kaganawa \\
\hline Kiyomi & & $\bigcirc$ & & Kinto & Early Crawford & - & Shizuoka \\
\hline Okubo & & & & Chance se & in Hakuto Orchard & - & Okayama \\
\hline Shimizu Hakuto & $\bigcirc$ & $\bigcirc$ & & Chance seedling ir & to and Okayama 3 orchard & - & Okayama \\
\hline Sanekoubai & & $\bigcirc$ & & & variety & - & Aomori \\
\hline Nunome Wase & & $\bigcirc$ & & & seedling & 1951 & Aichi \\
\hline Kurakata Wase & & $\bigcirc$ & & & & 1951 & Tokyo \\
\hline Nakatsu Hakuto & & $\bigcirc$ & $\bigcirc$ & Hakuto O.P. & & 1955 & Nara \\
\hline Sunago Wase & & & & & seedling & 1958 & Okayama \\
\hline Asama Hakuto & $\bigcirc$ & $\bigcirc$ & & Koyo Hakuto bud mutat & & - & Yamanashi \\
\hline Akatsuki & & & 0 & Hakuto & Hakuho & 1979 & NIFTS \\
\hline Kawanakajima Hakuto & $\bigcirc$ & $\bigcirc$ & 0 & & seedling & - & Nagano \\
\hline Ikeda (Nagano) & & & & & & - & Nagano \\
\hline Ogonto & $\bigcirc$ & $\bigcirc$ & & & seedling & - & Nagano \\
\hline Takei Hakuho & $\bigcirc$ & $\bigcirc$ & & Chance se & in Hakuho orchard & - & Yamanashi \\
\hline Reiho & & $\bigcirc$ & & Akatsuki bud mutation & & - & Yamanashi \\
\hline Hikawa Hakuho & $\bigcirc$ & $\bigcirc$ & & Hakuho bud mutation & & 1981 & Yamanashi \\
\hline Benishimizu & & 0 & & & seedling & 1983 & Okayama \\
\hline Saotome & $\bigcirc$ & $\bigcirc$ & & Hakuho & Robin & 1983 & NIFTS \\
\hline Kanouiwa Hakuto & $\bigcirc$ & $\bigcirc$ & & Asama Hakuto bud mut & & 1983 & Yamanashi \\
\hline Yuzora & & $\bigcirc$ & 0 & Hakuto & Akatsuki & 1983 & NIFTS \\
\hline Sweet Nectarine Shoko & & $\bigcirc$ & & Sotta Nectarine & Independence & 1984 & Yamanashi \\
\hline Sweet Nectarine Reimei & $\bigcirc$ & $\bigcirc$ & & Sotta Nectarine & Independence & 1984 & Yamanashi \\
\hline Abe Hakuto & $\bigcirc$ & $\bigcirc$ & & & seedling & 1985 & Hiroshima \\
\hline Nagasawa Hakuho & & $\bigcirc$ & & Hakuho bud mutation & & 1985 & Yamanashi \\
\hline Gyosei & 0 & $\bigcirc$ & & Akatsuki bud mutation & & 1986 & Fukushima \\
\hline Nishio Gold & & $\bigcirc$ & & Golden Peach bud muta & & 1988 & Okayama \\
\hline Chiyohime & $\bigcirc$ & $\bigcirc$ & & Koyo Hakuto & Saotome & 1988 & NIFTS \\
\hline Chiyomaru & 0 & $\bigcirc$ & & Momo Tsukuba 100 & Nunome Wase O.P.-2 & 1989 & NIFTS \\
\hline Odoroki & & $\bigcirc$ & & Hakuho bud mutation & & 1991 & Nagano \\
\hline Benikunimi & & $\bigcirc$ & & Akatsuki & Akatsuki & 1992 & Fukushima \\
\hline Masahime & $\bigcirc$ & $\bigcirc$ & & $21-18$ & Akatsuki & 1993 & NIFTS \\
\hline Yoshihime & $\bigcirc$ & $\bigcirc$ & & $21-18$ & Akatsuki & 1993 & NIFTS \\
\hline Shizuku Red & & $\bigcirc$ & & 19-1 O.P. & & 1993 & NIFTS \\
\hline Akizora & $\bigcirc$ & 0 & & Nishino Hakuto & Akatsuki & 1995 & NIFTS \\
\hline Natsuki & & $\bigcirc$ & & Kawanakajima Hakuto & Chiyohime & 1999 & Nagano \\
\hline Natsukko & & $\bigcirc$ & & Kawanakajima Hakuto & Akatsuki & 2000 & Nagano \\
\hline Natsuotome & $\bigcirc$ & $\bigcirc$ & & Akatsuki & Yoshihime & 2002 & NIFTS \\
\hline Hatsuotome & & $\bigcirc$ & & Kurakata Wase & Chiyohime & 2003 & Fukushima \\
\hline Fukuotome & & $\bigcirc$ & & Kurakata Wase & Chiyohime & 2003 & Fukushima \\
\hline Hakushu & & & & U-9 & C2R19T182 & 2004 & NIFTS \\
\hline Himekonatsu & $\bigcirc$ & $\bigcirc$ & & 182-3 O.P. & & 2009 & NIFTS \\
\hline Tsukiakari & 0 & $\bigcirc$ & & Masahime & Akatsuki & 2010 & NIFTS \\
\hline Hinanotaki & 0 & $\bigcirc$ & & G-62-8 & G-62-8 & 2010 & NIFTS \\
\hline Tsukikagami & & $\bigcirc$ & & Momo Tsukuba 115 & Momo Tsukuba 105 & 2011 & NIFTS \\
\hline Tsukuba 119 & $\bigcirc$ & $\bigcirc$ & & Momo Tsukuba 116 & $203-1$ & - & NIFTS \\
\hline Tsukuba 120 & $\bigcirc$ & $\bigcirc$ & & Momo Tsukuba 116 & $203-1$ & - & NIFTS \\
\hline Tsukuba 122 & & $\bigcirc$ & & Sunglo & $135-37$ & - & NIFTS \\
\hline Tsukuba 124 & 0 & 0 & & Kawanakajima Hakuto & $252-4$ & - & NIFTS \\
\hline Tsukuba 130 & & & $\bigcirc$ & Mochizuki & Hakushu & - & NIFTS \\
\hline Canning peach & & & & & & & \\
\hline Kanto 5 & & $\bigcirc$ & & $(\mathrm{Ki} \times \mathrm{T} 43)$ & (Kohai $3 \times$ Orange Cling 9) & 1956 & NIFTS \\
\hline Nishiki & $\bigcirc$ & 0 & & Kanto 12 & Kanto 2 & 1964 & NIFTS \\
\hline First Gold & & $\bigcirc$ & & Nishiki & Hiratsuka 39 & 1982 & NIFTS \\
\hline Sweet Gold & & 0 & & Fortuna & Kanto 5 & 1982 & NIFTS \\
\hline Early Gold & & 0 & & Nishiki & Fortuna & 1982 & NIFTS \\
\hline Mochizuki & $\bigcirc$ & $\bigcirc$ & $\bigcirc$ & Momo Tsukuba 115 & $139-28$ & 2000 & NIFTS \\
\hline Introduced for researcl & from $\mathrm{c}$ & er col & ries to & Japan & & & \\
\hline Elberta & & $\bigcirc$ & & Chinese Cling O.P. & & 1870 & U.S.A. \\
\hline Taikobanto & & 0 & & & & - & China \\
\hline Maravilha & & $\bigcirc$ & & Sunred & (Okinawa $\times$ Hiland) O.P. & 1975 & U.S.A. \\
\hline Harson & & $\bigcirc$ & & Redskin & Sunhaven & 1982 & Canada \\
\hline EVG-2 & & $\bigcirc$ & & & & - & \\
\hline Chimarrita & & $\bigcirc$ & & Babcock & Flordabelle & 1987 & Brazil \\
\hline
\end{tabular}

${ }^{\mathrm{z}}$ Listed in chronological order of year released. - indicates that the year of cultivar registration or release is uncertain, or unreleased selection. y Open pollinated seedling. 
2. Varietal differences in disease resistance to peach bacterial spot (Exp. 2)

Sixty-nine peach cultivars/selections (listed in Table 1), consisting of 57 table peach cultivars/ selections, which had been grown or are presently grown commercially in Japan and selections that are being tested for future commercial production, 6 canning peach cultivars/selections and 6 peach cultivars introduced from foreign countries for research use, were tested. Every cultivar/selection was tested for two years from 2006 to 2008 in the same way as described in Exp. 1. As in Exp. 1, the value of $(X-5.5)$ was used as the value showing the effect of the bacterial inoculation, and $\log _{10}(X-5.5)$ was calculated as the shoot measured value.

\section{Effect of different times of inoculation and concentra-} tions of inoculum on lesion length (Exp. 3)

Six cultivars or selections ('Mochizuki', 'Akatsuki', 'Yuzora', 'Kawanakajima Hakuto', 'Nakatsu Hakuto', and Momo Tsukuba 130) were used. Six current shoots per cultivar/selection were chosen at three times: May, June, and July, and three current shoots per cultivar/ selection and three sites per shoot were wounded by multiple-needle injections with the bacterial suspension of $10^{6} \mathrm{cfu} \cdot \mathrm{mL}^{-1}$ or $10^{8} \mathrm{cfu} \cdot \mathrm{mL}^{-1}$ in 2009 . Inoculated shoots were collected, and the average lesion length $(\mathrm{mm})$ on each shoot $(X)$ was measured in late August. As in Exp. 1 and Exp. 2, the value of $(X-5.5)$ was used as the value showing the effect of the bacterial inoculation, and $\log _{10}(X-5.5)$ was calculated as the shoot measured value.

The three shoot measured values for each cultivar (genotype) and treatment were subjected to ANOVA. The model adopted here to express the phenotypic value is shown below:

$$
\begin{aligned}
P_{i j k l}= & \mu+g 2_{i}+t_{j}+c_{k}+(g t)_{i j}+(g c)_{i k}+(t c)_{j k}+(g t c)_{i j k} \\
& +e 2_{i j k l}
\end{aligned}
$$

where $P_{i j k l}$ is the $l$ th shoot measured value of the $i$ th genotype of the $j$ th time in the $k$ th concentration; $\mu$ is a constant value (the overall mean); $g 2_{i}$ is the fixed effect contributed to by the $i$ th genotype; $t_{j}$ is the fixed effect contributed to by the $j$ th time; $c_{k}$ is the fixed effect contributed to by the $k$ th concentration, $(g t)_{i j}$ is the interaction between the $i$ th genotype and the $j$ th time; $(g c)_{i k}$ is the interaction between the $i$ th genotype and the $k$ th concentration; $(t c)_{j k}$ is the interaction between the $j$ th time and the $k$ th concentration; $(g t c)_{i j k}$ is the interaction among the $i$ th genotype, the $j$ th time and the $k$ th concentration; $e 2_{i j k l}$ is the error in the $l$ th shoot of the $i$ th genotype of the $j$ th time at the $k$ th concentration.

Distribution of the error estimate, which was obtained as the deviation of each shoot measured value from the average shoot measured value in a cultivar, time and concentration, approached normal distribution with the Kolmogorov-Smirnov one-sample test at $(P=0.05)$.

\section{Results}

\section{Yearly effect and the genotype $x$ year interaction for lesion length}

The result of ANOVA showed that the effect of genotype was significant $(P<0.01)$, and the effect of year was not significant $(P>0.05)$ (Table 2$)$. The interaction between the cultivar and the year was significant at $(P<0.01)$ (Table 2). The variance components of cultivar $\left(\sigma_{g}^{2}\right)$, year $\left(\sigma_{y}^{2}\right)$, the cultivar $\times$ year interaction $\left(\sigma_{g y}{ }^{2}\right)$, and error $\left(\sigma^{2}\right)$, were estimated as $0.045,0,0.016$, and 0.058 , respectively (Table 3 ).

\section{Varietal differences in disease resistance to peach bacterial spot}

Bacterial spot lesions that developed on some cultivars after inoculation are shown in Figure 2. All cultivars/ selections had longer lesions than the control. The lesion length data $\left(\log _{10}(\mathrm{X}-5.5)\right)$ for the 69 peach cultivars/ selections artificially inoculated with bacterial suspension are presented in Figure 3. The log-transformed lesion lengths ranged from 0.476 for 'Chimarrita' to 1.606 for 'Nakatsu Hakuto'. Comparing white-fleshed cultivars/selections and yellow-fleshed cultivars/selections, there seemed to be no relationship between flesh color and lesion length. The mean lesion length value of the 57 table peach cultivars/selections in Japan was 1.090 , nearly the same value as that of 'Shanghai Suimitao' (1.045). From a chronological perspective, the lesion lengths of older cultivars seemed to not differ from those of newer cultivars.

Using the error variance $\left(\sigma_{e l}^{2}\right)$ in Exp. 1, SE and $\mathrm{LSD}_{0.05}$ were calculated. Each cultivar/selection value that was calculated as the average value for two years

Table 2. Analysis of variance of lesion lengths $\left(\log _{10}(X-5.5)\right)$ in the artificial innoculation test to shoot with 25 cultivars/selections from 2006 to 2008 (Exp. 1) $)^{2}$.

\begin{tabular}{lcrcrc}
\hline \hline Source of variation & Sum of square & d.f. & Mean square & $F$-value & Expected MS \\
\hline Cultivar/selection & 12.301 & 24 & 0.513 & $8.85^{* *}$ & $\sigma_{e 1^{2}+3 \sigma_{g y}{ }^{2}+9 \sigma_{g 1^{2}}}$ \\
Year & 0.128 & 2 & 0.064 & $1.10^{\mathrm{NS}}$ & $\sigma_{e 1^{2}+3 \sigma_{g y}{ }^{2}+75 \sigma_{y}{ }^{2}}$ \\
Cultivar $\times$ year & 5.052 & 48 & 0.105 & $1.81^{* *}$ & $\sigma_{e 1^{2}+3 \sigma_{g y}{ }^{2}}$ \\
Error & 8.681 & 150 & 0.058 & $\sigma_{e 1^{2}}$ \\
Total & 26.162 & 224 & & & \\
\hline
\end{tabular}

Ns, ** Nonsignificant $(P>0.05)$, or significant $(P<0.01)$, respectively.

${ }^{\mathrm{z}} X$ indicates lesion length for each shoot. 
Table 3. Variance components estimated by the analysis of variance for lesion lengths in the artificial innoculation test to shoot with 25 cultivars/selections from 2006 to 2008 (Exp. 1).

\begin{tabular}{lcc}
\hline \hline Variance component & Estimate & $\begin{array}{c}\text { Percentage of variance } \\
\text { component to the sum of the } \\
\text { variance components }(\%)\end{array}$ \\
\hline$\sigma_{g l^{2}}$ (cultivar) & 0.045 & 37.8 \\
$\sigma_{y}^{2}$ (year) & 0 & 0.0 \\
$\sigma_{g y}{ }^{2}$ (cultivar $\times$ year) & 0.016 & 13.4 \\
$\sigma_{e 1}{ }^{2}$ (error) & 0.058 & 48.7 \\
\hline
\end{tabular}

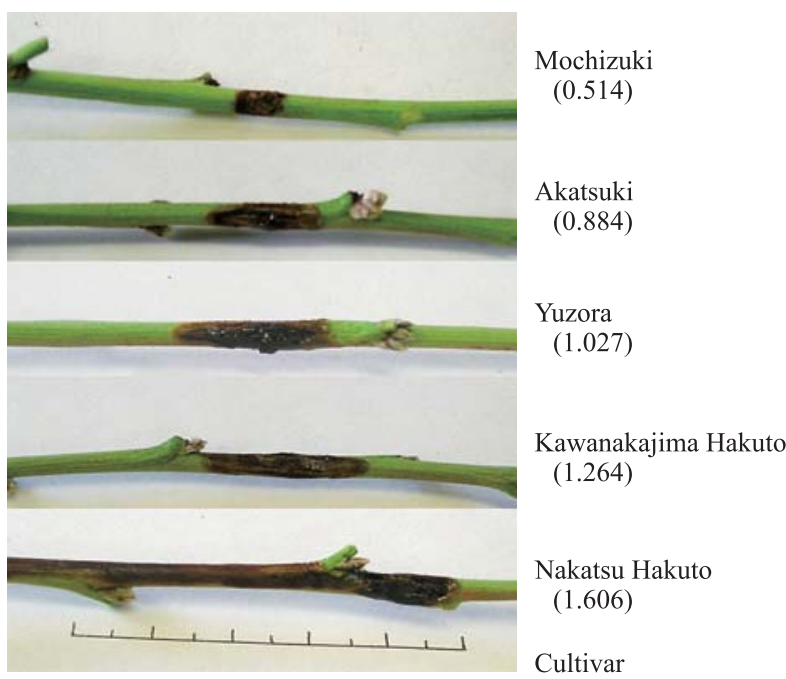

Fig. 2. Artificially inoculated lesions on current shoots of some cultivars. Lesion length $\left(\log _{10}(\mathrm{X}-5.5)\right)$ is shown in parentheses.

had an error variance $\left(\sigma_{E}^{2}\right)$ of $\left\{\left(\sigma_{g y}{ }^{2}+\sigma_{e 1}{ }^{2} / 3\right)\right\} / 2=0.018$ and $\mathrm{SE}$ of 0.132 . $\mathrm{LSD}_{0.05}$ was calculated as 0.367 . The phenotypic variance for cultivar/selection $\left(\sigma_{P}^{2}\right)$, which was the variance among the cultivar/selection values, was estimated as 0.061 . The genetic variance $\left(\sigma_{G}^{2}\right)$ in the whole population was estimated as $\sigma_{P}^{2}-\sigma_{E}^{2}$, and 0.043. Broad-sense heritability, defined as $\sigma_{G}{ }^{2} / \sigma_{P}{ }^{2}$, was 0.71 . The genetic variances were estimated as 0.030 , 0.090 , and 0.074 for 57 Japanese table peach cultivars/ selections, 6 canning cultivars, and 6 foreign cultivars, respectively.

\section{Effect of different times of inoculation and concentra- tions of inoculum on lesion length}

All the effects of the factors and their interactions were highly significant $(P<0.01)$ except for the effect of the inoculation time (Table 5). The estimates shown as $\kappa^{2}$ in Table 5 were used as indicators showing the extent of the effect or interaction, and the percentages of each $\kappa^{2}$ or the error variance $\sigma_{e 2}{ }^{2}$ to the sum of $7 \kappa^{2}$ and $\sigma_{e 2}{ }^{2}$ were calculated (Table 6). The percentage for cultivar was the largest $(44.0 \%)$, followed by that for the cultivar $\times$ time interaction $(14.3 \%)$, then the inoculum concentration $(13.7 \%)$, and the cultivar $\times$ concentration interaction $(12.8 \%)$. The percentage was $6.8 \%$ for the cultivar $\times$ time $\times$ concentration interaction, $6.7 \%$ for the

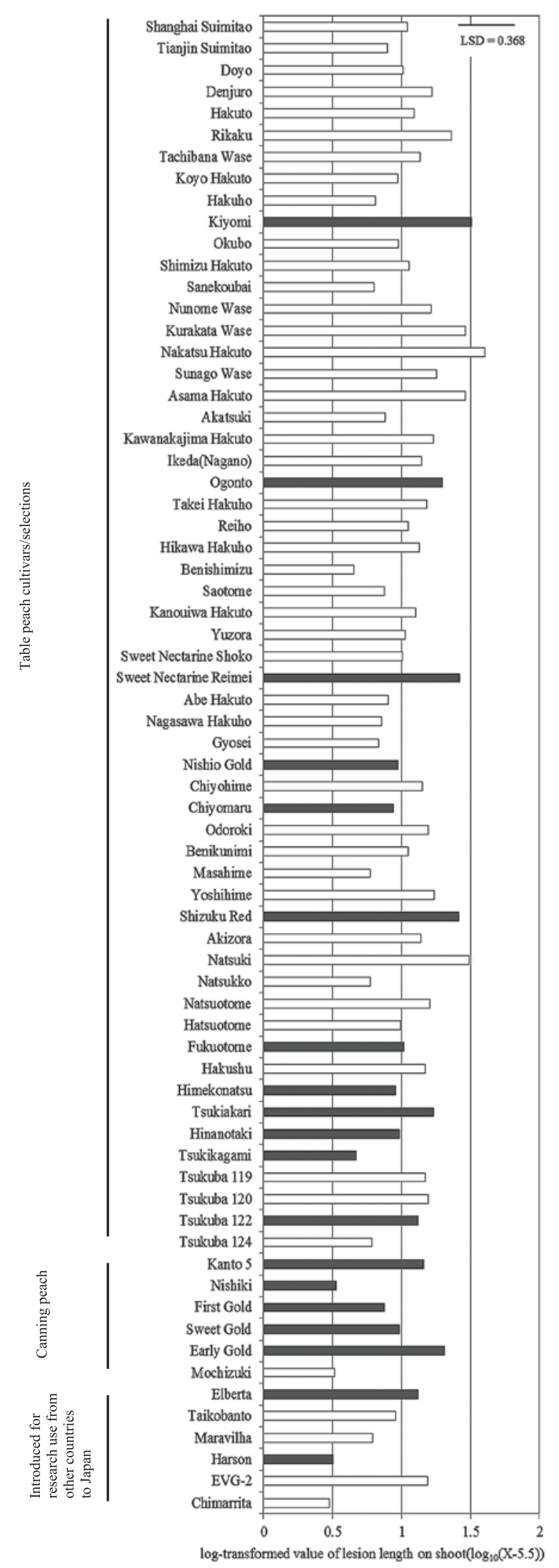

Fig. 3. Varietal differences in log-transformed lesion length $\left(\log _{10}(X\right.$ $-5.5)$ ) of artificially inoculated peach shoots (2006-2008). X is the original value for lesion length. Solid and open columns indicate yellow-fleshed and white-fleshed cultivars/selections, respectively. 
Table 4. Lesion length resulting from the artifical innoculation test to shoot with different inoculation times and inoculum concentrations (Exp. 3).

\begin{tabular}{|c|c|c|c|c|c|c|c|c|}
\hline \multirow{3}{*}{ Cultivar/selection } & \multirow{3}{*}{$\begin{array}{c}\text { Inoculum } \\
\text { concentration }\end{array}$} & \multicolumn{7}{|c|}{ Legion length (mm) } \\
\hline & & \multicolumn{6}{|c|}{ Inoculation time } & \multirow{2}{*}{ Average } \\
\hline & & \multicolumn{2}{|c|}{ May } & \multicolumn{2}{|c|}{ June } & \multicolumn{2}{|c|}{ July } & \\
\hline \multirow[t]{2}{*}{ Momo Tsukuba 130} & $10^{6} \mathrm{cfu} \cdot \mathrm{mL}^{-1}$ & 8.7 & $(0.505)^{\mathrm{z}}$ & 10.4 & $(0.688)$ & 11.8 & $(0.796)$ & 10.3 \\
\hline & $10^{8} \mathrm{cfu} \cdot \mathrm{mL}^{-1}$ & 9.2 & $(0.573)$ & 14.9 & $(0.975)$ & 16.4 & (1.039) & 13.5 \\
\hline \multirow[t]{2}{*}{ Akatsuki } & $10^{6} \mathrm{cfu} \cdot \mathrm{mL}^{-1}$ & 6.4 & $(-0.060)$ & 11.3 & $(0.763)$ & 12.1 & $(0.823)$ & 9.9 \\
\hline & $10^{8} \mathrm{cfu} \cdot \mathrm{mL}^{-1}$ & 13.3 & $(0.893)$ & 15.2 & $(0.986)$ & 16.4 & (1.038) & 15.0 \\
\hline \multirow[t]{2}{*}{ Kawanakajima Hakuto } & $10^{6} \mathrm{cfu} \cdot \mathrm{mL}^{-1}$ & 35.8 & $(1.482)$ & 17.0 & $(1.061)$ & 8.0 & $(0.395)$ & 20.3 \\
\hline & $10^{8} \mathrm{cfu} \cdot \mathrm{mL}^{-1}$ & 44.0 & $(1.586)$ & 15.9 & (1.018) & 14.5 & $(0.957)$ & 24.8 \\
\hline \multirow[t]{2}{*}{ Nakatsu Hakuto } & $10^{6} \mathrm{cfu} \cdot \mathrm{mL}^{-1}$ & 44.2 & $(1.588)$ & 40.0 & $(1.537)$ & 27.7 & $(1.346)$ & 37.3 \\
\hline & $10^{8} \mathrm{cfu} \cdot \mathrm{mL}^{-1}$ & 53.6 & $(1.682)$ & 32.7 & $(1.435)$ & 29.2 & $(1.375)$ & 38.5 \\
\hline \multirow[t]{2}{*}{ Mochizuki } & $10^{6} \mathrm{cfu} \cdot \mathrm{mL}^{-1}$ & 6.0 & $(-0.312)$ & 6.2 & $(-0.164)$ & 5.9 & $(-0.428)$ & 6.0 \\
\hline & $10^{8} \mathrm{cfu} \cdot \mathrm{mL}^{-1}$ & 9.4 & $(0.595)$ & 8.7 & $(0.504)$ & 12.3 & $(0.832)$ & 10.1 \\
\hline \multirow[t]{2}{*}{ Yuzora } & $10^{6} \mathrm{cfu} \cdot \mathrm{mL}^{-1}$ & 8.5 & $(0.472)$ & 16.4 & (1.039) & 16.5 & $(1.042)$ & 13.8 \\
\hline & $10^{8} \mathrm{cfu} \cdot \mathrm{mL}^{-1}$ & 12.9 & $(0.871)$ & 15.9 & (1.018) & 16.8 & (1.053) & 15.2 \\
\hline \multirow[t]{2}{*}{ Average } & $10^{6} \mathrm{cfu} \cdot \mathrm{mL}^{-1}$ & 18.3 & & 16.9 & & 13.7 & & 16.3 \\
\hline & $10^{8} \mathrm{cfu} \cdot \mathrm{mL}^{-1}$ & 23.8 & & 17.2 & & 17.6 & & 19.5 \\
\hline
\end{tabular}

${ }^{\mathrm{z}}$ Average legion length of three shoots. Number in parentheses indicate log-transformed value $\left(\log _{10}(X-5.5)\right)$.

$X$ indicates lesion length for each shoot.

Table 5. Analysis of variance for lesion length $\left(\log _{10}(X-5.5)\right)$ resulting from the artifical innoculation test to shoot under different inoculation conditions; inoculation time and inoculum concentration (Exp. 3$)^{z}$.

\begin{tabular}{lccccc}
\hline \hline \multicolumn{1}{c}{ Source of variation } & Sum of square & d.f. & Mean square & $F$ value & Expected MS \\
\hline Cultivar/Selection & 17.550 & 5 & 3.510 & $119.26^{* *}$ & $\sigma_{e 2^{2}+18 \kappa_{g 2^{2}}}$ \\
Inoculum concentration & 3.275 & 1 & 3.275 & $111.26^{* *}$ & $\sigma_{e 2^{2}+54 \kappa_{c}{ }^{2}}$ \\
Inoculation time & 0.139 & 2 & 0.069 & $2.35^{\mathrm{NS}}$ & $\sigma_{e 2^{2}}+36 \kappa_{t}^{2}$ \\
Cultivar $\times$ concentration & 2.671 & 5 & 0.534 & $18.15^{* *}$ & $\sigma_{e 2^{2}}{ }^{2}+9 \kappa_{g c}{ }^{2}$ \\
Cultivar $\times$ time & 4.071 & 10 & 0.407 & $13.83^{* *}$ & $\sigma_{e 2^{2}}+6 \kappa_{g t^{2}}$ \\
Time $\times$ concentration & 0.303 & 2 & 0.152 & $5.15^{* *}$ & $\sigma_{e 2^{2}}{ }^{2}+18 \kappa_{t c}{ }^{2}$ \\
Cultivar $\times$ concentration $\times$ time & 1.188 & 10 & 0.119 & $4.04^{* *}$ & $\sigma_{e 2^{2}}{ }^{2}+3 \kappa_{g c t}{ }^{2}$ \\
Error & 2.119 & 72 & 0.029 & & $\sigma_{e 2^{2}}$ \\
\hline Total & 31.315 & 107 & & & \\
\hline
\end{tabular}

Ns, ** Nonsignificant $(P>0.05)$, or significant $(P<0.01)$, respectively.

${ }^{\mathrm{z}} X$ indicates lesion length for each shoot.

Table 6. Variance components estimated by the analysis of variance for lesion lengths in the artifical innoculation test to shoot under different inoculation conditions; inoculation time and inoculum concentration (Exp. 3).

\begin{tabular}{lcc}
\hline \hline Variance component & Estimate & $\begin{array}{c}\text { Percentage of each } \\
\text { variance component to } \\
\text { the sum of the variance } \\
\text { components }(\%)\end{array}$ \\
\hline$\kappa_{g 2^{2}}{ }^{2}($ cultivar $)$ & 0.193 & 44.0 \\
$\kappa_{c}^{2}$ (inoculum concentration) & 0.060 & 13.7 \\
$\kappa_{t}^{2}$ (inoculation time) & 0.001 & 0.3 \\
$\kappa_{g c}{ }^{2}($ cultivar $\times$ conc. $)$ & 0.056 & 12.8 \\
$\kappa_{g t}{ }^{2}($ cultivar $\times$ time $)$ & 0.063 & 14.3 \\
$\kappa_{t c}{ }^{2}($ time $\times$ conc. $)$ & 0.007 & 1.5 \\
$\kappa_{g t c}{ }^{2}($ cultivar $\times$ time $\times$ conc. $)$ & 0.030 & 6.8 \\
$\sigma_{e 2}{ }^{2}($ error $)$ & 0.029 & 6.7 \\
\hline
\end{tabular}

error, and $0.3 \%$ for the inoculation time.

While the lesion length of 'Kawanakajima Hakuto' and 'Nakatsu Hakuto' was the largest in May and the smallest in July, that of 'Akatsuki' and 'Yuzora' was the largest in July and the smallest in May (Table 4). The cultivar $\times$ time interaction was significant $(\mathrm{P}<0.01)$ (Table 5).

Average lesion lengths were $16.3 \mathrm{~mm}$ and $19.5 \mathrm{~mm}$ for inocula of $10^{6} \mathrm{cfu} \cdot \mathrm{mL}^{-1}$ and $10^{8} \mathrm{cfu} \cdot \mathrm{mL}^{-1}$, respectively (Table 4), and the effect of the inoculum concentration was highly significant (Table 5). The effect was significant, meaning that cultivar performance shifted in parallel depending on the inoculum concentration.

\section{Discussion}

Inoculation methods to evaluate susceptibility

The result of ANOVA for cultivar/selection and year showed that the effect of the genotype was significant 
and the effect of the year was not (Exp. 1). No significance of the effect of the year and little year effect in Exp. 1 mean that yearly environmental conditions have little effect on lesion lengths. The condition of peach trees may be stable, irrespective of the year tested. The data from different test years can be directly combined and compared.

Different inoculation times and inoculum concentrations were tried to determine suitable conditions for conducting the inoculation test. Current shoots of suitable size (30-40 cm long, and $5 \mathrm{~mm}$ basal diameter) for artificial inoculation were not available in sufficient quantity at NIFTS in May and July. There were shorter shoots in May and longer and thicker shoots in July. Since it was easier to obtain shoots in June than in May and July, June is recommended as the best time to inoculate shoots at this location. Although the effect of time was not significant, cultivar $\times$ time interaction was significant $(P<0.01)$. This result may be contributed to by 'Kawanakajima Hakuto', whose lesion lengths were notably larger in May than in June and July.

\section{Varietal differences for susceptibility}

Among the 69 cultivars/selections tested, there was no completely immune cultivar; however, there were varietal differences in susceptibility to bacterial spot. Peach breeding has been carried out with an emphasis on fruit quality within a small gene pool derived from 'Shanghai Suimitao' in Japan (Yamamoto et al., 2003). Japanese table peach cultivars/selections had small genetic variance in their resistance to bacterial spot. There were only 2 cultivars with significantly lower values ('Benishimizu' and 'Tsukikagami') and only 6 cultivars with significantly higher values ('Nakatsu Hakuto', 'Kiyomi', 'Asama Hakuto', 'Kurakatawase', 'Sweet Nectarine Reimei', and 'Shizuku Red') than the value of 'Shanghai Suimitao', respectively, based on the LSD. On the other hand, 'Chimaritta' and 'Harson' from the 6 foreign cultivars and 'Michizuki' and 'Nishiki' from the 6 canning cultivars/selections had significantly lower values.

Cultivars developed in areas where bacterial spot is a serious problem generally show more resistance than other cultivars selected in regions with less frequent occurrence of the disease (Keil and Fogle, 1974; Topp and Sherman, 1995; Werner et al., 1986). Therefore, cultivars that had been developed in areas prone to bacterial spot were compared with those developed in areas with infrequent occurrence of bacterial spot. In Japan, Kanagawa, Aichi, and Nara Prefectures have sustained the most serious damage from bacterial spot, whereas Yamanashi, Fukushima, and Okayama Prefectures have rarely reported the occurrence of the disease (Takanashi, 1980). The cultivars selected in Kanagawa, Aichi, and Nara, including 'Denjuro', 'Tachibana Wase', 'Hakuho', 'Nunome Wase', and 'Nakatsu Hakuto', had a mean value of 1.197 , whereas the 21 cultivars released from Yamanashi, Fukushima, and Okayama, including 'Doyo', 'Hakuto', 'Rikaku', 'Koyo Hakuto', 'Ookubo', and 'Shimizu Hakuto', had a mean value of 1.069 (Table 1). The difference was very small, and the relationship between the original area of the cultivar and resistance was not clear. In addition, susceptibility did not seem to change chronologically (Fig. 3), suggesting the lack of bacterial spot resistance selection in peach breeding in Japan.

The tested cultivars/selections included 4 siblings: 'Sweet Nectarine Reimei' (1.424) and 'Sweet Nectarine Shoko' (1.006), 'Masahime' (0.771) and 'Yoshihime' (1.235), 'Hatsuotome' (0.993) and 'Fukuotome' (1.020), 'Tsukuba 119' (1.194) and 'Tsukuba 120' (1.172). Lesion lengths were similar for two sibling pairs, 'Hatsuotome' and 'Fukuotome', 'Tsukuba 119', and 'Tsukuba 120', but were not similar in the other sibling pairs. The inheritance of resistance to bacterial spot should be elucidated by a crossing experiment.

From this study, 'Chimarrita' (0.476), a Brazilian lowchilling requirement cultivar, 'Harson' (0.504), a Canadian cultivar, 'Mochizuki' (0.514), and 'Nishiki' $(0.522)$ had low values for lesion length and were selected as relatively resistant. 'Chimarrita' does not have adequate fruit quality for production in Japanese climates. 'Nishiki' and 'Mochizuki' are canning peach cultivars (Kajiura et al., 1966; Yamaguchi et al., 2001) and have non-melting flesh, unlike most table peach cultivars in Japan.

The inheritance of bacterial spot resistance should be investigated. If we assume quantitative inheritance and proceed to the first step of breeding based on phenotypic values, non-table peach cultivars, such as 'Nishiki' and 'Mochizuki', two canning peaches, and 'Harson' and 'Chimarrita', foreign cultivars, should be cross-parent candidates for the initial crosses. In addition, Japanese table peach cultivars/selections with high eating quality from the peach breeding program should be used as cross-parents with the aim of combining the resistance to bacterial spot with fruit quality. Notably, 'Tsukikagami', a table peach cultivar, was relatively resistant and may be useful genetic material for breeding.

\section{Literature Cited}

Du Plessis, H. J. 1988. Differential virulence of Xanthomonas campestris pv. pruni to peach, plum and apricot cultivars. Phytopathology 78: 1312-1315.

Kajiura, M., K. Kanato, A. Kurihara, M. Yoshida, K. Matsuda, T. Sato and R. Harada. 1966. New canning peach variety 'Nishiki'. Hort. Exp. Rep. A, Hiratsuka 5: 131-138.

Keil, H. L. and H. W. Fogle. 1974. Orchard susceptibility of some apricot, peach and plum cultivars and selections to Xanthomonas pruni. Fruit Var. J. 28: 16-19.

Kuraoka, E. and S. Kato. 1955. Experiment of bacterial spot of peach. Fruit Tree Exp. Rep. A., Shizuoka: 312-314 (In Japanese).

Martins, O. M. and M. C. B. Raseira. 1996. Sources of bacterial spot resistance in plum cultivars. Fruit Var. J. 50: 156-159. 
Medeiros, J. G. S., I. Citadin, I. dos Santos and A. P. Assmann. 2011. Reaction of peach to genotypes to bacterial leaf spot caused by Xanthomonas arboricola pv. pruni. Sci. Agric. (Piracicaba, Braz.) 68: 57-61.

Miyake, M., H. Yaegaki, T. Haji and M. Yamaguchi. 1999. Screening of resistance to bacterial spot caused by Xanthomonas campestris pv. pruni among Japanese plum (Prunus salicina Lindl.) and several Prunus species by artificial inoculation on shoots. Bull. Natl. Inst. Fruit Tree Sci. 33: 77-96 (In Japanese with English abstract).

Randhawa, P. S. and E. L. Civerolo. 1985. A detached leaf bioassay for Xanthomonas campestris pv. pruni. Phytopathology 75: $1060-1063$.

Sherman, W. B. and P. M. Lyrene. 1981. Bacterial spot susceptibility in low chilling peaches. Fruit Var. J. 35: 74-77.

Shiina, T., T. Shoji and S. Suzuki. 1966. Studies on the resistance of peach varieties to the infection of bacterial spot, Xanthomonas pruni (E. F. Smith) Dowson, in the sand hill of Shonai district. Bull. Yamagata Agri. Exp. Sta. 1: 99-101 (In Japanese).

Takanashi, K. 1978. Ecological studies on bacterial spot caused by Xanthomonas pruni (E. F. Smith) Dowson. Bull. Fruit Tree Res. Sta. A5: 1-71 (In Japanese with English summary).

Takanashi, K. 1980. Ecology and control on bacterial spot caused by Xanthomonas pruni (E. F. Smith) Dowson. Plant Protection
(Syokubutsu-Boueki) 34: 485-489 (In Japanese).

Topp, B. L., W. B. Sherman and R. E. Stall. 1991. Comparison of rating methods for bacterial spot resistance in Japanesetype plum. Fruit Var. J. 45: 70-74.

Topp, B. L. and W. B. Sherman. 1995. Plum bacterial spot resistance in leaves and stems measured by a selection index. Acta Hort. 403: 47-50.

Werner, D. J., D. F. Ritchie, D. W. Cain and E. I. Zehr. 1986 Susceptibility of peaches and nectarines, plant introductions, and other Prunus species to bacterial spot. HortScience 21: 127-130.

Yamaguchi, M., H. Kyotani, M. Yoshida, T. Haji, K. Nishimura, Y. Nakamura, M. Miyake, H. Yaegaki, K. Tanaka, Y. Ishikawa, T. Kihara, K. Suzuki, H. Fukuda and T. Asakura. 2001. New canning peach cultivar 'Mochizuki' with white flesh. Bull. Natl. Inst. Fruit Tree Sci. 35: 33-45 (In Japanese with English abstract).

Yamamoto, T., K. Mochida and T. Hayashi. 2003. Shanhai Suimitsuto, one of the origins of Japanese peach cultivars. J. Japan. Soc. Hort. Sci. 72: 116-121.

Yamamoto, Y., C. Ogaki and Y. Tatsuno. 1953. Experiments and investigations on the bacterial spot of peach. 1) Effects of weather condition on outbreak of the disease, and susceptibility in the varieties of peach. Bull. Kanagawa Agri. Exp. Sta. 1: 57-62 (In Japanese with English summary). 